\title{
Multidimensional Structural Credit Modeling under Stochastic Volatility
}

\author{
Marcos Escobar, ${ }^{1}$ Tim Friederich, ${ }^{2}$ Luis Seco, ${ }^{3}$ and Rudi Zagst ${ }^{4}$ \\ ${ }^{1}$ Ryerson University, Toronto, Canada M5B 2 K3 \\ ${ }^{2}$ Technische Universität München, 85748 München, Germany \\ ${ }^{3}$ RiskLab Toronto at the University of Toronto, Toronto, Canada M5S 2E4 \\ ${ }^{4}$ Chair of Mathematical Finance, Technische Universität München, 85748 München, Germany \\ Correspondence should be addressed to Marcos Escobar; escobar@ryerson.ca
}

Received 13 April 2013; Accepted 8 May 2013

Academic Editors: P. D’Urso, M. Galea, P. E. Jorgensen, and S. Sagitov

Copyright (C) 2013 Marcos Escobar et al. This is an open access article distributed under the Creative Commons Attribution License, which permits unrestricted use, distribution, and reproduction in any medium, provided the original work is properly cited.

\begin{abstract}
This paper extends the structural credit model with underlying stochastic volatility to a multidimensional framework. The model combines the Black/Cox framework with the Heston model interpreting the equity of a company as a down-and-out barrier call option on the company's assets. This implies a combination of local and stochastic volatility on the equity as well as other stylized features. In this paper, we allow for a correlation between the asset processes of different companies to incorporate dependency structures. An estimator for the correlation parameter is derived and tested in a recovery framework. With the help of this model, we examine the default risk of the two mortgage lenders Fannie Mae and Freddie Mac before their actual placement into federal conservatorship and show that their default risk severely increased during the financial crisis.
\end{abstract}

\section{Introduction}

In this paper we combine a structural credit model with the Heston model of stochastic volatility in a multidimensional framework. In [1] the value of the equity of a company is modeled as a down-and-out barrier call option on the company's assets with its liabilities as strike price, following the motivation of structural credit models, for example, by [2] or [3]. As markets have shown, in particular during the financial crisis, volatility is not constant over time. This is why we enhanced the classical structural credit model by providing the asset process with a stochastic volatility such as in the Heston model (see [4]). This simple assumption implies that the volatility of the log-equity is a function of the equity itself (a local volatility feature) as well as the stochastic volatility component of the asset process. The correlation between the volatility of the equity and the equity is also nonzero and negative allowing for the leverage effect reported in the literature.

In [1] the default risk of Merrill Lynch was examined utilizing the structural credit model with stochastic volatility. As recent events have shown defaults are unlikely to incur independently. This is why we extend this model to multidimensions by assuming correlation between the asset processes of the companies involved. This dependence structure implies the same level of correlation on the companies' equity while keeping a rich marginal process for the equities.

This paper derives an estimator for the correlation parameter of the assets based on the method of moments which, together with estimators already presented in [1] for the volatility parameters, allows for a full set of closed-form estimators of the model parameters. These estimators are consistent and quick to be found numerically as shown in this paper which is highly beneficial to practitioners in part due to the negligent literature on consistent estimators for continuous time process with stochastic covariance. With this setup we scrutinize another core event of the financial crisis: the downfall of the two mortgage-lenders Fannie Mae and Freddie Mac. The joint probabilities as well as conditional probabilities of defaults are highlighted providing some explanation to their behavior during the 2008 financial crisis.

This paper is organized as follows. Section 2 presents the multidimensional stochastic covariance processes for the 
assets as well as the implied process for the equity within a Black-Cox structural framework. Properties of the implied multivariate equity process are also provided. Section 3 focuses on the calibration method of the multivariate process of the assets and the volatilities based on observing the equity series and their debt. The recovery of the parameters is also shown in Section 3.1. Section 4 studies in detail the cases of Fannie Mae and Freddie Mac. Section 5 concludes the paper.

\section{The Multidimensional Stochastic Volatility Model}

In [1] a stochastic volatility model is presented to describe the process of a company's assets and the equity of that company is modeled as a barrier call option on its assets. This model will now be generalized to a multi-dimensional framework allowing for correlation between the asset processes of different companies. We restrict ourselves to presenting the twodimensional model which of course can be expanded to as many dimensions as desired.

Let $(\Omega, \mathscr{F}, \mathbb{F}, \mathbb{Q})$ be a filtered probability space with filtration $\mathbb{F}=\left\{\mathscr{F}_{t}\right\}_{t \geq 0}$. QQ stands for the risk-neutral measure. The underlying asset process $A_{j}$ of company $j$ and the according variance $v_{j}$ can be expressed through the following SDEs:

$$
\begin{gathered}
d A_{j}(t)=r A_{j}(t) d t+\sqrt{v_{j}(t)} A_{j}(t) d Z_{j}(t) \quad j \in\{1,2\}, \\
d v_{j}(t)=\kappa_{v, j}\left(v_{\infty, j}-v_{j}(t)\right) d t+\varepsilon_{v, j} \sqrt{v_{j}(t)} d Z_{j}^{v}(t) \\
\left.d Z_{1}(t) d Z_{2}(t)=\rho d t, 2\right\}, \\
d Z_{1}^{v}(t) d Z_{2}^{v}(t)=0, \\
d Z_{i}(t) d Z_{j}^{v}(t)=0 \quad i, j \in\{1,2\},
\end{gathered}
$$

where $A_{j}=$ underlying asset process, $v_{j}=$ variance of asset process, where the volatility $\sigma_{A_{j}}=\sqrt{v_{j}}, \mu_{j}=$ drift of the assets, $Z_{j}, Z_{j}^{v}=$ two independent Wiener processes in the probability space $(\Omega, \mathscr{F}, \mathbb{Q}), v_{\infty, j}=$ long-term value of variance, $\varepsilon_{v, j}=$ volatility of the variance process, $\kappa_{v, j}=$ meanreversion speed of the variance process, and $\rho=$ correlation between the Wiener processes $Z_{1}(t)$ and $Z_{2}(t)$.

In order to guarantee that the process of the variance is always greater than zero, the parameters $v_{\infty}, \kappa_{v}$, and $\varepsilon_{v}$ have to fulfill the so-called Feller condition (see [5]):

$$
\begin{gathered}
\kappa_{v} \cdot v_{\infty} \geq \frac{1}{2} \varepsilon_{v}^{2}, \\
\kappa_{v}>0 .
\end{gathered}
$$

We further assume the liabilities $D_{j}$ of company $j$ to grow exponentially with the risk-free rate $r$ as

$$
D_{j}(t)=D_{j}(0) \cdot e^{\int_{0}^{t} r d s}=D_{j}(T) \cdot e^{-\int_{t}^{T} r d s}
$$

The model defined by (1) and (2) is a so-called stochastic volatility model and also referred to as "Heston Model" due to the fact that it had been introduced by [4]. This model setup is further examined in the one-dimensional case in [1]. The variance process was first used by [6] to model interest rates.

Technically, the two asset processes 1 and 2 are correlated by modeling their Wiener processes $Z_{1}(t)$ and $Z_{2}(t)$ with a correlation $\rho$. This means that, when considering companies, not the actual stock prices are modeled with a correlation, but their underlying asset. This is a realistic assumption, because companies operate on correlated markets depending on their field of business, and it is rather the assets where a correlation can be suggested economically. However, this does not necessarily determine their equity to have exactly the same covariance, due to different organizational structures, operating models, or leverage ratios, and so forth.

The equity value of company $j$ is now modeled as a downand-out call option on the company's assets with its liabilities as strike price. The down-and-out call option has the feature that the option expires worthless, if the value of the assets falls below the barrier at any point in time. The value of the barrier option with strike and barrier $D(T)$ on the company's assets $A$ is

$$
\begin{aligned}
C( & (t, A) \\
& =\mathbb{E}_{\mathbb{Q}}\left[e^{-\int_{t}^{T} r(s) d s} \cdot \max \{A(T)-D(T), 0\} \cdot \mathbf{1}_{\{\tau>T\}} \mid \mathscr{F}_{t}\right],
\end{aligned}
$$

where $C(t, A)$ is the option price of the barrier option with underlying $A$ at time $t$, and $\tau$ is time of default of the option, that is, the first time the asset process $A$ crosses the barrier $D$. $\tau$ is modeled as a stopping time on the interval $\left(0, T^{*}\right]$ as

$$
\tau=\inf \left\{t^{\prime} \in\left(0, T^{*}\right]: A\left(t^{\prime}\right)<D\left(t^{\prime}\right)\right\} .
$$

The symbol $\mathbb{E}_{\mathbb{Q}}$ denotes the expected value under the arbitrage-free measure $\mathbb{Q}$.

The payoff of the option described by (10) is zero if the assets are below the liabilities at maturity or at any time before maturity. Thus, the stopping time $\tau$ can be interpreted as the time of default of the company. The value of this option, that is, the value of the company at time $t$, has already been derived in [1] by the means of optional sampling (see [7]) as

$$
C(t, A)=(A(t)-D(t)) \cdot \mathbf{1}_{\{\tau>t\}} \cdot
$$

This result can alternatively be gained by simplifying the formula derived in the more general framework in [8], in which the barrier and strike price are allowed to attain different values.

Next we provide several properties of the joint process for the equities which match stylized facts described in the literature like stochastic volatility and leverage effect. The first set of results focuses on the instantaneous properties of the joint process.

Proposition 1. Assume a two-dimensional equity vector $\left(C_{i}(t\right.$, $\left.A_{i}\right), C_{j}\left(t, A_{j}\right)$ ) where each equity process is defined as in (10). 
Then the quadratic variation of the equity, the covariation between the log-equities, and the correlation between the logequity and its volatility are

$$
\begin{gathered}
\langle d \ln C(t)\rangle=v_{\ln C} \cdot \mathbf{1}_{\{\tau>t\}}, \\
v_{\ln C}=v(t) \cdot g(t), \\
\left\langle d \ln C_{i}(t), d \ln C_{j}(t)\right\rangle=\sqrt{v_{i}(t) v_{j}(t) g_{i}(t) g_{j}(t)} \\
\cdot \mathbf{1}_{\left\{\tau_{i}>t\right\}} \cdot \mathbf{1}_{\left\{\tau_{j}>t\right\}} \rho d t, \\
\frac{\left\langle d \ln C(t), d v_{\ln C}\right\rangle}{\sqrt{\langle d \ln C(t)\rangle\left\langle d v_{\ln C}\right\rangle}} \\
=-\frac{2 v(t) \cdot(D(t) / C(t))}{\sqrt{4 v^{2}(t)(D(t) / C(t))^{2}+\varepsilon_{v}^{2}}} \cdot \mathbf{1}_{\{\tau>t\}} \\
=-\frac{v(t)}{\sqrt{v^{2}(t)+\left((1 / 2) \varepsilon_{v} \cdot(C(t) / D(t))\right)^{2}}} \cdot \mathbf{1}_{\{\tau>t\}},
\end{gathered}
$$

where $g(t)=(1+D(t) / C(t))^{2}=(A(t) / C(t))^{2}$.

For a proof see Appendix A.

Equation (11) shows the quadratic variation for the logequity with (12) being the volatility of the log-equity process. The quadratic covariation is given in (13), while the correlation between the log-equity and its variation is given in (15). This last equation is evidence that the leverage effect is not only negative as described in the literature (see [9]) but also stochastic. Figure 1 shows the correlation between the equity and its variance for several values of leverage $(D / C)$ and asset's volatility. This confirms the leverage effect implied by the model. The parameters for this figure are chosen as follows: $\varepsilon_{v}=0.025, v \in[0.00001,0.01], D(t) / C(t) \in[0,20]$, (no other parameters necessary here). Another important stylized fact related to the joint behaviour is the correlation between the equities. It is not difficult to see that our model implies a constant instantaneous correlation $\rho$ between the equities. Still the advantage of the model lies on the term structure of conditional correlations (correlation versus time to maturity; see [10]), which is indeed affected by the level of the debt and the volatility of the underlying company leading to a richer dependence structure than that of a standard lognormal process. The term structure of conditional correlations is important for derivatives on the equity. While lognormal processes imply a constant term structure, reality shows that the longer the horizon the lower the probability of comovements (see implied correlation findings in [11]). Our model implies a decreasing conditional correlation with time to maturity. The following proposition focuses on these issues.

Proposition 2. Assume a two-dimensional equity vector $\left(C_{i}\left(t, A_{i}\right), C_{j}\left(t, A_{j}\right)\right)$ where each equity process is defined as in (10). Then the instantaneous correlation $\rho(t, d t)$ and the conditional correlation $\rho(t, T)$ between the log-equity processes are

$$
\begin{aligned}
\rho(t, d t) & =\frac{\left\langle d \ln C_{i}(t), d \ln C_{j}(t)\right\rangle}{\sqrt{\left\langle d \ln C_{i}(t)\right\rangle\left\langle d \ln C_{j}(t)\right\rangle}} \\
& =\rho \cdot \mathbf{1}_{\left\{\tau_{i}>t\right\}} \cdot \mathbf{1}_{\left\{\tau_{j}>t\right\}},
\end{aligned}
$$

Note that if the debt is zero in (16) and volatility is constant (or independent) then the conditional correlation $\rho(t, T)=\rho$ as in the case of a lognormal processes. So there are two separate sources for this nonconstant correlation structure, the presence of debt and of a stochastic equity volatility. Figure 2 shows the conditional correlation at a given $t$, as a function of $T-t$ and the leverage. The parameters used in this simulation are given next: $r=0.03, v(0)=$ $v_{\infty}=0.0009(\sigma(0)=0.03), \kappa=1.5, \varepsilon_{v}=0.025, \rho=0.5$, $T-t \in[0.5,5], D(t) / C(t) \in[0,20]$.

These conditional correlations are computed conditioning on no default from either one of the underlyings. The correlation slightly decreases with time to maturity starting on the instantaneous correlation. The leverage has also an impact on the correlation as the higher the leverage the smaller the conditional correlation. This last observation does not contradict the notion that companies with high leverage have higher probabilities of defaulting (increased contagion effect) as we are computing the conditional correlations given no default. Note that volatilities were assumed uncorrelated, and based on simulations, they have little impact on the conditional correlation behavior, (17). The decreasing (in maturity time) conditional correlation on the equities together with the constant (and higher) conditional correlation of the assets implied by our model shows the importance for practitioners to know not only the equity values but also the true level of leverage of a company in order to assess the right dependence structure between the companies.

\section{Calibrating the Model in the Multidimensional Case}

What we observe on the market are time series for the value of a company, that is, its equity price, or in terms of the model, 


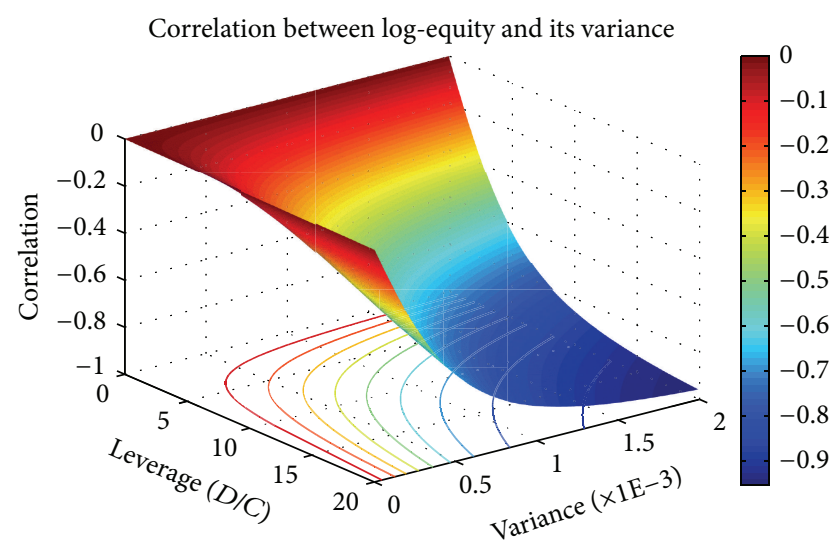

FIGURE 1: Correlation between log-equity and its variance subject to leverage and variance.

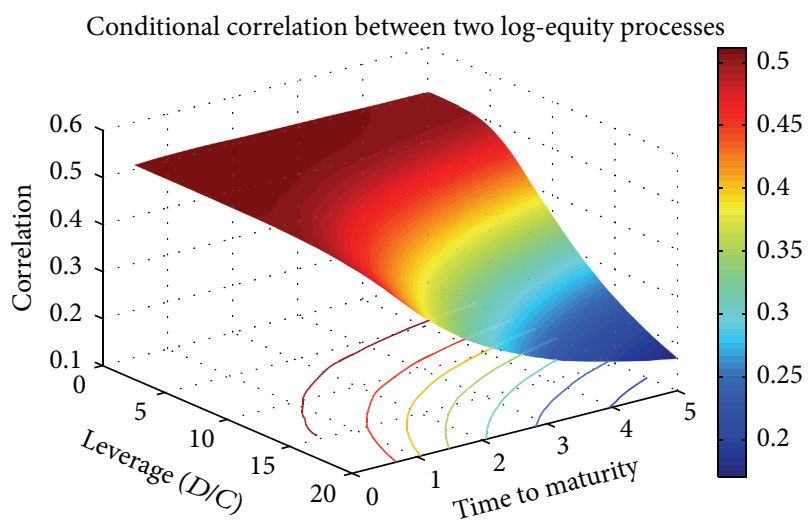

FIGURE 2: Correlation between two log-equity processes subject to leverage and time to maturity.

the value of the barrier option. The option pricing formula (10) allows for a straight-forward inverse to calculate the value of the company's assets if its equity price and level of debt are known. In order to calibrate the model parameters $\Theta_{j}=\left(\mu_{j}, v_{\infty, j}, \kappa_{v, j}, \varepsilon_{v, j}\right)$ for two companies' asset processes and the correlation parameter $\rho$, we need to derive estimators.

The estimators to gain the parameters $\Theta_{j}$ for the single processes are already shown in [1]. We also follow along these lines when deriving the estimator for the correlation parameter $\rho$.

First, define $Y_{j}=\log A_{j}$. Then, according to Itô's Lemma,

$$
d Y_{j}(t)=\left(\mu_{j}-\frac{v_{j}(t)}{2}\right) d t+\sqrt{v_{j}(t)} d Z_{j}(t)
$$

With the partition $\left\{t_{i}\right\}_{i=1}^{n}$ of the time interval $[0, t]$ where $t_{i}=$ $i \Delta$, and

$$
\begin{gathered}
R_{j}(i)=\left(\mu_{j}-\frac{\bar{V}_{j}(i)}{2}\right) \cdot \sqrt{\Delta}+\frac{1}{\sqrt{\Delta}} \int_{(i-1) \Delta}^{i \Delta} \sqrt{v_{j}(s)} d Z_{j}(s), \\
\bar{V}_{j}(i)=\frac{1}{\Delta} \int_{(i-1) \Delta}^{i \Delta} v_{j}(s) d s,
\end{gathered}
$$

it holds that

$$
R_{j}(i)=\frac{Y_{j}(i \Delta)-Y_{j}((i-1) \Delta)}{\sqrt{\Delta}} .
$$

Proposition 3. For the process $R(i) \in\left\{R_{1}(i), R_{2}(i)\right\}$ with corresponding $\bar{V}(i) \in\left\{\bar{V}_{1}(i), \bar{V}_{2}(i)\right\}$, defined by (19), there exist the following estimators:

$$
\begin{gathered}
\frac{1}{n} \sum_{i=0}^{n-1} R(i+1) \stackrel{\text { a.s. }}{\longrightarrow} \sqrt{\Delta} \mu-\frac{\sqrt{\Delta}}{2} \mathbb{E}[\bar{V}(1)], \\
\frac{1}{n-1} \sum_{i=0}^{n-2} R(i+1) R(i+2) \stackrel{\text { a.s. }}{\longrightarrow} \Delta \mu^{2}-\Delta \mu \mathbb{E}[\bar{V}(1)] \\
+\frac{\Delta}{4} \mathbb{E}[\bar{V}(1) \bar{V}(2)], \\
\frac{1}{n} \sum_{i=0}^{n-1} R^{2}(i+1) \stackrel{\text { a.s. }}{\longrightarrow} \Delta \mu^{2}-(\Delta \mu-1) \mathbb{E}[\bar{V}(1)]+\frac{\Delta}{4} \mathbb{E}\left[\bar{V}^{2}(1)\right], \\
\frac{1}{n-1} \sum_{i=0}^{n-2} R^{2}(i+1) R(i+2) \\
\stackrel{a . s .}{\longrightarrow}\left(\Delta \mu^{2}-(\Delta \mu-1) \mathbb{E}[\bar{V}(1)]+\frac{\Delta}{4} \mathbb{E}\left[\bar{V}^{2}(1)\right]\right) \\
\cdot\left(\sqrt{\Delta} \mu-\frac{\sqrt{\Delta}}{2} \mathbb{E}[\bar{V}(1)]\right), \\
\frac{1}{n} \sum_{i=0}^{n-1} R^{4}(i+1) \stackrel{a . s .}{\longrightarrow} \Delta^{2} \mu^{4}+\left(6 \Delta \mu^{2}-2 \Delta^{2} \mu^{3}\right) \mathbb{E}[\bar{V}(1)] \\
+\left(\frac{3}{2} \Delta^{2} \mu^{2}-6 \Delta \mu+3\right) \mathbb{E}\left[\bar{V}^{2}(1)\right] .
\end{gathered}
$$

Those estimators can be applied to each process separately. And for gaining the pairwise correlation parameter between any two processes 1 and 2, it holds that

$$
\begin{aligned}
\frac{1}{n} \sum_{i=0}^{n-1} R_{1}(i+1) R_{2}(i+1) \stackrel{\text { a.s. }}{\longrightarrow} & \rho \cdot \mathbb{E}\left[\bar{V}_{1}^{1 / 2}(1)\right] \mathbb{E}\left[\bar{V}_{2}^{1 / 2}(1)\right] \\
+ & \left(\sqrt{\Delta} \mu_{1}-\frac{\sqrt{\Delta}}{2} \mathbb{E}\left[\bar{V}_{1}(1)\right]\right)
\end{aligned}
$$




$$
\begin{array}{r}
\cdot\left(\sqrt{\Delta} \mu_{2}-\frac{\sqrt{\Delta}}{2} \mathbb{E}\left[\bar{V}_{2}(1)\right]\right) \\
\text { for } \Delta \rightarrow 0,
\end{array}
$$

where

$$
\begin{gathered}
\mathbb{E}[\bar{V}(1)]=v_{\infty}, \\
\mathbb{E}\left[\bar{V}^{2}(1)\right]=v_{\infty}^{2}+\frac{\varepsilon_{v}^{2} v_{\infty}}{\kappa_{v}} \frac{\left(\kappa_{v} \Delta-1+e^{-\kappa_{v} \Delta}\right)}{\kappa_{v}^{2} \Delta^{2}}, \\
\mathbb{E}[\bar{V}(1) \bar{V}(2)]=v_{\infty}^{2}+\frac{\varepsilon_{v}^{2} v_{\infty}}{2 \kappa_{v}} \frac{\left(1-e^{-\kappa_{v} \Delta}\right)^{2}}{\kappa_{v}^{2} \Delta^{2}}, \\
\mathbb{E}\left[\bar{V}^{1 / 2}(1)\right]=\frac{\Gamma\left(2 v_{\infty} \kappa_{v} / \varepsilon_{v}^{2}+0.5\right)}{\Gamma\left(2 v_{\infty} \kappa_{v} / \varepsilon_{v}^{2}\right)} \cdot \frac{\varepsilon_{v}}{\sqrt{2 \kappa_{v}}} .
\end{gathered}
$$

For a proof see Appendix A.

These estimators are used for calibrating the time series to the stochastic volatility model by minimizing the sum of squared residuals between the empirical estimators on the left-hand side and the theoretical estimators on the righthand side. For calibrating the two-dimensional model, first the parameters $\Theta_{1}$ and $\Theta_{2}$ are estimated for each time series and then the correlation parameter with the help of (21).

3.1. Applying the Model and Recovering the Parameters. In order to test the validity of the presented fitting method, a recovery test is conducted. For such a test, we assume a given set of parameters $\left(\Theta_{1}, \Theta_{2}, \rho\right)$, simulate a set of time series according to the model described by (1) and (2), and calculate the equity time series applying the option pricing formula (10). These equity time series are the input for the fitting method which then yields the estimated parameters $\left(\widehat{\Theta}_{1}, \widehat{\Theta}_{2}, \widehat{\rho}\right)$. We do this for $N=10000$ simulated time series and then compare the estimated parameter sets to the initial parameter set.

The test is set up as follows. We first assume the two asset processes to have the same parameters $\Theta_{1}=\Theta_{2}=$ $\left(\mu, v_{\infty}, \kappa_{v}, \varepsilon_{v}\right)=(0.05,0.01,0.75,0.1):=\Theta^{(1)}$ and choose the correlation parameter $\rho \in\{-0.5,-0.25,0,0.25,0.5,0.75\}$. For each $\rho$ we then simulate $N=10,000$ correlated daily asset paths for both asset series over 100 years. Furthermore, we set the following parameters: $D_{1}(0)=4, D_{2}(0)=4$, and $r=0.03$. As we assume the equity process to start with $C(0)=1$ w.l.o.g., this corresponds to a leverage ratio (defined as the ratio between debt and equity capital) of 4 . The parameter which might be hardest to find is the time to maturity for the debt. However, we found that the sensitivity towards $T$ is very small and does not influence the estimation compared to the other parameters substantially. Thus, we assumed that $T=5$ which seems to be a fair proxy for the financing horizon of a company. However, the parameters $\left(\Theta_{1}, \Theta_{2}, \rho\right)$ are not directly observable on the market and have to be estimated. It is important to mention that we only consider those time series which did not default over time; that is, for all simulated days $i \in[1, n]$ the assets do not fall below the liabilities $A(i) \geq D(i)$. This naturally already implies a "survivorship bias" in the results, which will also be discussed later on.

Table 1 summarizes the outcomes of this test. The upper half aggregates the estimators for the parameters $\widehat{\Theta}_{1}$ and $\widehat{\Theta}_{2}$ for all different correlation parameters; that is, these statistics are based on a sample size of 60,000. From top to bottom, the table gives information on the true parameters $\mu, v_{\infty}, \kappa_{v}$, and $\varepsilon_{v}$, the mean of the estimated parameters, and the parametric standard deviation. Further information on the parametric distribution is provided in the last three lines stating the $5 \%$ quantile, the median, and the $95 \%$ quantile. The fitted parameters are close to the initial parameters, yet there seems to be a deviation in a certain direction which, however, can be explained by the survivorship bias, as only those time series were calibrated which did not default. Thus, it comes as no surprise that the mean of the drift is slightly higher than the initial $\mu$, because those time series with a lower drift are more likely to default. If we had assumed a lower leverage ratio this would, of course, have decreased the likelihood of defaults and thus the influence of the survivorship bias on the fitted parameters, but at the same time it would have created a less realistic test setting. The same obviously holds for the slight underestimation of the long-term variance $v_{\infty}$, as higher variance increases the likelihood of a default. Though not that straight forward, the deviations for $\kappa_{v}$ can also be explained. A higher $\kappa_{v}$ means that the volatility of the variance is not as high as for a low mean-reversion speed and decreases the probability of extreme events caused by (momentarily) high variance, and thus the probability for defaults. Same as in [8], the parametric standard deviation indicates that the parameters $\mu$ and $v_{\infty}$ can be captured with a higher precision than $\kappa_{v}$ and $\varepsilon_{v}$ which are describing the unobservable variance process and thus are harder to grasp.

The second part of the table presents the results for the different examined correlation parameters $\rho$ and gives the same statistics as aforementioned. The outcomes for the correlation parameters are very satisfying. For each of the values for the initial correlation the means of the fitted parameters $\hat{\rho}$ are very close to the true values, and at the same time the parametric standard deviation is quite low promising a high accuracy when capturing the correlation.

A second test is done in the same manner, but with different parameters for the asset processes. Table 2 presents the results of a test where the asset processes have been simulated with the initial parameters $\Theta_{1}=\Theta_{2}=\left(\mu, v_{\infty}, \kappa_{v}, \varepsilon_{v}\right)=$ $(0.075,0.04,1.5,0.25):=\Theta^{(2)}$. For this parameter set, the drift is higher than before, yet at the same time the variance is much higher, and so is the volatility of the variance process. Thus, comparing the results for $\widehat{\Theta}$ of this table to the ones in Table 1, we can see that the "survivorship bias" effect is even more visible for the new set of initial parameters. This is the case, in particular, for the drift, as the drift of course has most influence on whether a company defaults or not. The correlation parameter $\rho$ again could nicely be recovered. Comparing the statistics of fitted $\hat{\rho}$ for the two different sets of initial asset process parameters, the asset process parameters hardly seem to have an effect on the quality of estimating the correlation parameter $\hat{\rho}$. 
TABLE 1: Recovering the parameters with different values for $\rho$ (with $\Theta^{(1)}$ ).

(a)

\begin{tabular}{lcccc}
\hline \multirow{2}{*}{ True parameter } & $\widehat{\mu}$ & $\widehat{v_{\infty}}$ & $\widehat{\kappa_{v}}$ & $\widehat{\varepsilon_{v}}$ \\
& 0.0500 & 0.0100 & 0.7500 & 0.1000 \\
\hline Mean & 0.0572 & 0.0095 & 0.9746 & 0.1146 \\
std. & 0.0126 & 0.0029 & 0.3754 & 0.0378 \\
\hline 5\% quantile & 0.0382 & 0.0056 & 0.4592 & 0.0714 \\
Median & 0.0561 & 0.0090 & 0.9109 & 0.1094 \\
95 quantile & 0.0795 & 0.0148 & 1.5999 & 0.1846 \\
\hline
\end{tabular}

(b)

\begin{tabular}{lcccccc}
\hline True parameter & & & & $\hat{\rho}$ & & \\
& -0.5000 & -0.2500 & 0.0000 & 0.2500 & 0.5000 & 0.7500 \\
\hline Mean & -0.4916 & -0.2457 & 0.0004 & 0.2467 & 0.4933 & 0.7398 \\
std. & 0.0283 & 0.0176 & 0.0121 & 0.0179 & 0.0285 & 0.0404 \\
\hline $5 \%$ quantile & -0.5384 & -0.2753 & -0.0199 & 0.2192 & 0.4490 & 0.6788 \\
Median & -0.4904 & -0.2449 & 0.0002 & 0.2453 & 0.4906 & 0.7372 \\
95 quantile & -0.4474 & -0.2191 & 0.0211 & 0.2770 & 0.5429 & 0.8092 \\
\hline
\end{tabular}

TABLE 2: Recovering the parameters with different values for $\rho$ (with $\Theta^{(2)}$ ).

(a)

\begin{tabular}{lcccc}
\hline True parameter & $\widehat{\mu}$ & $\widehat{v_{\infty}}$ & $\widehat{\kappa_{v}}$ & $\widehat{\varepsilon_{v}}$ \\
& 0.0750 & 0.0400 & 1.5000 & 0.2500 \\
\hline Mean & 0.0969 & 0.0396 & 1.7593 & 0.2434 \\
std. & 0.0244 & 0.0053 & 1.2981 & 0.1074 \\
\hline 5\% quantile & 0.0603 & 0.0316 & 0.3797 & 0.1192 \\
Median & 0.0946 & 0.0393 & 1.3887 & 0.2138 \\
95 quantile & 0.1408 & 0.0490 & 4.7672 & 0.5045 \\
\hline
\end{tabular}

(b)

\begin{tabular}{lcccccc}
\hline True parameter & & \multicolumn{3}{c}{$\hat{\rho}$} & & \\
& -0.5000 & -0.2500 & 0.0000 & 0.2500 & 0.5000 & 0.7500 \\
\hline Mean & -0.4976 & -0.2487 & 0.0006 & 0.2498 & 0.4989 & 0.7480 \\
std. & 0.0133 & 0.0117 & 0.0113 & 0.0117 & 0.0133 & 0.0164 \\
\hline 5\% quantile & -0.5202 & -0.2681 & -0.0177 & 0.2309 & 0.4779 & 0.7221 \\
Median & -0.4972 & -0.2486 & 0.0009 & 0.2497 & 0.4987 & 0.7476 \\
95 quantile & -0.4770 & -0.2300 & 0.0189 & 0.2693 & 0.5211 & 0.7757 \\
\hline
\end{tabular}

Finally, we also want to examine whether it makes a difference for the estimation of the correlation parameter if the two asset processes are not the same (as for the previous two tests) but have different initial parameters. For this purpose, we simulated the asset time series of the first company with $\Theta^{(1)}$ and the second with $\Theta^{(2)}$. Table 3 gives the results for the estimated correlation parameters $\hat{\rho}$. The outcomes for the asset process parameters $\widehat{\Theta}_{1}$ and $\widehat{\Theta}_{2}$ are in line with the results in Tables 1 and 2 . When examining these correlation parameters, we can reject the hypothesis that the estimation quality suffers if the two assets processes are simulated with two different parameter sets, this is due to the fact that the true parameter lies in the $95 \%$ confidence interval based on the estimator. The means are still very close to the true values, and the empirical distribution does not change when comparing the values of Table 3 to those of Tables 1 and 2 .

\section{Case Study: Fannie Mae and Freddie Mac}

In this section, we are applying the two-dimensional stochastic volatility model to a real-world case examining the financial situation and the risks of Fannie Mae and Freddie Mac. The history of Fannie Mae has always been largely influenced by crises. In 1938, Fannie Mae was founded as part of President Roosevelt's "New Deal" under the name "Federal National Mortgage Association." Its purpose was to 
TABLE 3: Recovering the parameters with different values for $\rho$.

\begin{tabular}{lcccccc}
\hline True parameter & & & $\hat{\rho}$ & & & \\
& -0.5000 & -0.2500 & 0.0000 & 0.2500 & 0.5000 & 0.7500 \\
\hline Mean & -0.4945 & -0.2470 & 0.0004 & 0.2481 & 0.4956 \\
std. & 0.0181 & 0.0135 & 0.0118 & 0.0138 & 0.0186 & 0.0249 \\
\hline $5 \%$ quantile & -0.5243 & -0.2697 & -0.0196 & 0.2261 & 0.4674 & 0.7046 \\
Median & -0.4944 & -0.2467 & 0.0006 & 0.2476 & 0.4951 & 0.7424 \\
95 quantile & -0.4654 & -0.2251 & 0.0199 & 0.2716 & 0.5271 & 0.7854 \\
\hline
\end{tabular}

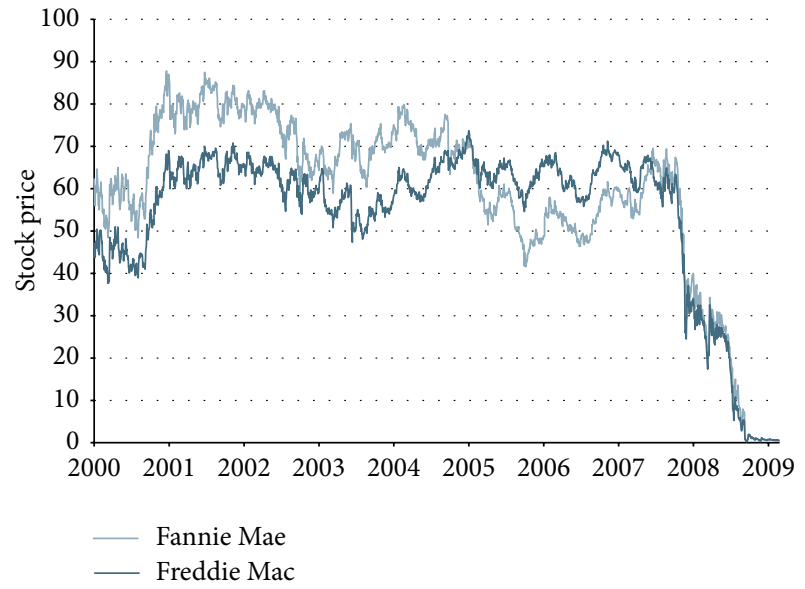

FIGURE 3: Stock price of Fannie Mae and Freddie Mac.

encourage private investors to invest in home loans again after the confusion of the Great Depression. The core business of Fannie Mae was to provide local banks with federal money, who could then charge low interest rates on mortgages for the benefit of the home buyers. This created the so-called secondary mortgage market. After its privatization in 1968, Fannie Mae operated as a Government Sponsored Enterprise (GSE), which allowed private investors to participate in Fannie Mae's shares, yet Fannie Mae still savored federal guarantees. In order to prevent a monopoly in the secondary mortgage market, the Federal Home Loan Mortgage Corporation (Freddie Mac) was founded in 1970. Thanks to the federal guarantees, refinancing has never been an issue for the two mortgage banks. But the decay of house prices in 2007 severely struck Fannie Mae and Freddie Mac and gave rise to doubts in their status as virtually unrisky creditors. This caused a fatal increase of their refinancing costs. In September 2008, they needed to refinance about 250 billion USD in debt. Neither agency has ever had difficulties in attracting subscribers to its monthly auctions. But now, insolvency only seemed a matter of time. On September 8, 2008, the Federal Housing Finance Agency (FHFA) announced to put Fannie Mae and Freddie Mac under its conservatorship. By making them issue new shares, the state holds $80 \%$ of both companies. That day, the value of their stocks decreased by approximately $80 \%$. The federal takeover of Fannie Mae and Freddie Mac may be deemed one of the most essential events of the financial crisis.
In order to study the situation of the two mortgage lenders, the input for the method presented in the previous sections is the time series of their equity, that is, their stock prices. Until 1999, their performance was characterized by a very low volatility and a positive drift. Since then, the volatility increased while the positive drift ceased, as shown in Figure 3. In mid-2007, the fatal decline began which destroyed approximately 70 billion dollars of the shareholders' equity capital. In the following, we will compare the situation of both companies at two points in time: before the decline and shortly after the outbreak of the crisis. The data this study is based on are the six years from July 2001 until June 2007 in the first and July 2002 until June 2008 in the second part. As Fannie Mae and Freddie Mac have a similar business model and operate on the same market, it is standing to reason that the assets of both corporations, and thus also their stock price, do not develop independently from each other. The two-dimensional stochastic volatility model accounts for such a dependence structure by correlating the underlying asset processes.

The first point in time we analyze is July 2007 based on the stock performance between July 2001 and June 2007. Before estimating the parameters $\left(\Theta_{1}, \Theta_{2}, \rho\right)$, we need to assess the exogenous parameters. In order to get an appropriate riskfree rate, we take the average 5-year US treasury rate over the considered time horizon, corresponding to the maturity of 5 years which has been discussed earlier. From the daily data drawn from the webpage of the US Treasury, we get $r=3.89 \%$. The leverage ratio $D(0)$ is taken from the annual reports of Fannie Mae and Freddie Mac: $D_{\mathrm{FNM}}(0)=32.2$ and $D_{\text {FRE }}(0)=26.6$.

The estimated parameters resulting from the fitting method are

\begin{tabular}{c|cccc} 
Est. parameters & $\widehat{\mu}$ & $\widehat{v_{\infty}}$ & $\widehat{\kappa_{v}}$ & $\widehat{\varepsilon_{v}}$ \\
Fannie Mae & 0.03703 & 0.00004083 & 7.796 & 0.01314 \\
\hline Freddie Mac & 0.03714 & 0.00004687 & 7.151 & 0.02346
\end{tabular}

The correlation parameter is $\rho=0.7026$.

Comparing the parameters for the two companies indicates that the variance of Freddie Mac is higher than the variance of Fannie Mae, and Freddie Mac's variance process has a higher volatility $\varepsilon_{v \text {,FRE }}$ itself. At the same time, Freddie Mac also has a slightly higher expected return of $3.714 \%$ compared to $3.703 \%$. It has to be mentioned that the longterm variances $v_{\infty, \mathrm{FNM}}$ and $v_{\infty, \mathrm{FRE}}$ seem to be very low, corresponding to asset price volatilities of $0.64 \%$ and $0.68 \%$, 


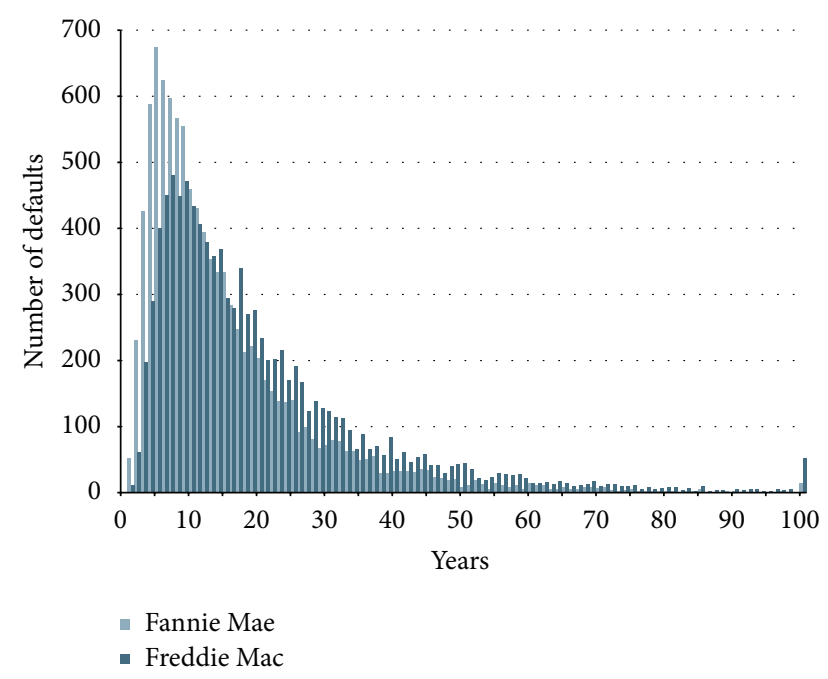

Figure 4: Defaults of simulated time series (July 2007).

respectively. However, these values can be explained taking into account the model assumptions and the setting of this problem. The model has one important assumption which is that the debt is deterministic; that is, it has no stochastic component and does not allow for a volatility of the returns of the debt. Thus, only the volatility of the equity can influence the volatility of the assets and vice versa. And the higher the leverage ratio of the companies the smaller the influence of the volatility of the equity process on the volatility of the asset process. However, later on, we use the same model to gain equity processes again (by simulating asset processes) which then have similar characteristics as the original equity time series. The estimated correlation of the asset process of 0.7026 already is a strong indicator for the similarity of the business models of both mortgage lenders.

For examining the default risk, 10,000 paths (each) are simulated daily over 100 years for Fannie Mae and Freddie Mac. The simulation of the time series starts in July 2007. For assessing the time of default the assets are compared to the debt. If the value of the debt exceeds the value of the assets the company defaults. The events of default are visualized in Figure 4. The bars show in how many of the 10,000 simulated paths the companies default in one particular year. In all cases, both companies survive the first year (i.e., from July 2007 until June 2008). In the second year, Fannie Mae would have to declare insolvency in 52 cases and Freddie Mac in 12. In only 15 cases Fannie Mae survives over the simulated 100 years. Freddie Mac survives 100 years in 53 scenarios (those are the last two bars in Figure 4). The graph shows that Fannie Mae faces a higher default risk than Freddie Mac. The probability of default is higher for Fannie Mae in the first years. The peak when most time series default is also different. The maximum number (674) of Fannie Mae defaults occurs in year 6, and the peak for Freddie Mac is two years later with 480 defaults in year 8 . Considering the total number of simulated time series of 10,000 for each corporation, these numbers can also be regarded as probabilities. For example, the probability to default within the first five years

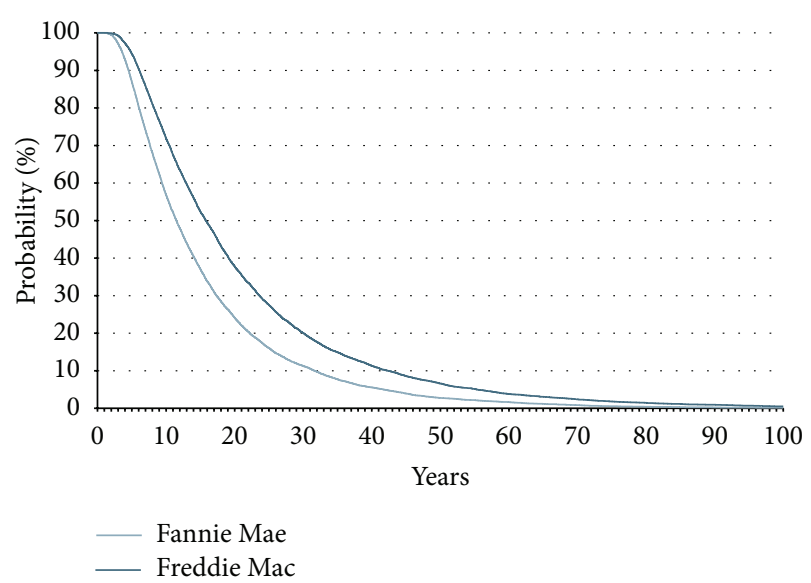

FIgURE 5: Survival probabilities for Fannie Mae and Freddie Mac (July 2007).

corresponds to the sum of the defaults assigned to the first five bars. For Fannie Mae, this probability equals $12.97 \%$, and for Freddie Mac it is $5.61 \%$. This corresponds to the probability of a default between July 2007 and June 2012. Figure 5 displays the probabilities to survive a respective number of years which is plotted on the $x$-axis. In general, it can be stated that the default probability is higher for Fannie Mae than for Freddie Mac, which is also due to the higher leverage of Fannie Mae-despite Freddie Mac having a higher volatility as discussed earlier. It is, furthermore, interesting to observe that in almost no case the companies are likely to survive in the long run (as opposed to, e.g., estimated for Merrill Lynch in [1] to survive 100 years with a probability of $41 \%$ ).

We can also find evidence for the dependence structure in the simulated paths. Assuming that the events of a default occurred independently, the probability that both companies default would be equal to the product of the probabilities that each company defaults

$$
\mathbb{Q}\left(D F_{t}(\mathrm{FNM}, \mathrm{FRE})\right)=\mathbb{Q}\left(D F_{t}(\mathrm{FNM})\right) \cdot \mathbb{Q}\left(D F_{t}(\mathrm{FRE})\right),
$$

where $\mathbb{Q}\left(D F_{t}(\mathrm{FNM})\right)$ denotes the probability that Fannie Mae has defaulted until $t$. The event of a default can occur any time before $t . \mathbb{Q}\left(D F_{t}(\mathrm{FRE})\right)$ and $\mathbb{Q}\left(D F_{t}(\mathrm{FNM}, \mathrm{FRE})\right)$ denote the default probabilities for Freddie Mac and both companies, respectively.

For example, when considering $t=5$ (years), the probabilities for a default of Fannie Mae and Freddie Mac are the following:

$$
\begin{aligned}
\mathbb{Q}\left(D F_{5}(\mathrm{FNM})\right) & =12.97 \%, \\
\mathbb{Q}\left(D F_{5}(\mathrm{FRE})\right) & =5.61 \%,
\end{aligned}
$$

and the probability that both companies default until $t=5$ is

$$
\mathbb{Q}\left(D F_{5}(\mathrm{FNM}, \mathrm{FRE})\right)=3.03 \% \text {. }
$$

However, according to (4), the joint probability is $\mathbb{Q}\left(D F_{5}(\mathrm{FNM})\right) \cdot \mathbb{Q}\left(D F_{5}(\mathrm{FRE})\right)=0.73 \%$ which is distinctly 


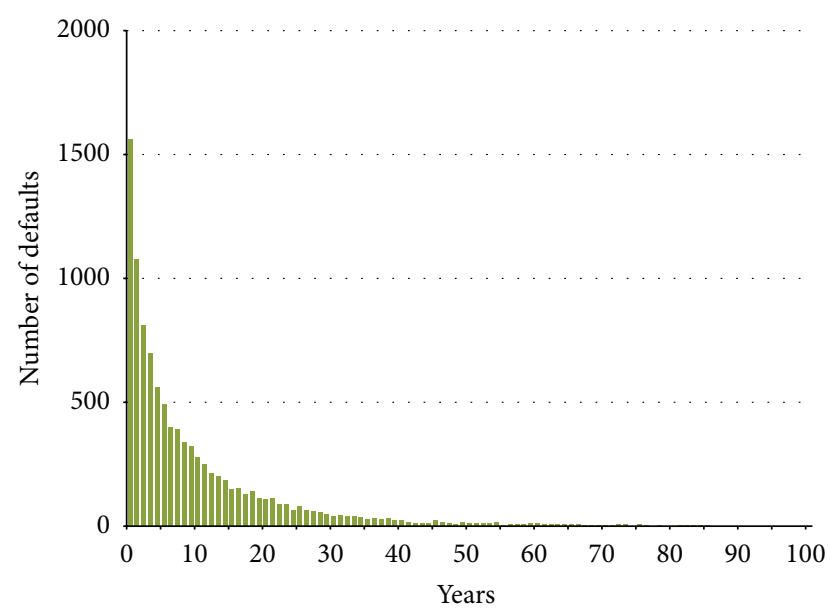

Figure 6: Time difference between first and second defaults (July 2007).

lower than the actual $3.03 \%$, hinting at a high correlation between the defaults of the two mortgage banks. In other words, defaults are more likely to occur together. This allows to calculate so-called conditional probabilities. For example,

$$
\begin{aligned}
\mathbb{Q}\left(D F_{t}(\mathrm{FNM}, \mathrm{FRE})\right)= & \mathbb{Q}\left(D F_{t}(\mathrm{FNM})\right) \\
& \cdot \mathbb{Q}\left(D F_{t}(\mathrm{FRE}) \mid D F_{t}(\mathrm{FNM})\right),
\end{aligned}
$$

where $\mathbb{Q}\left(D F_{t}(\mathrm{FRE}) \quad \mid \quad D F_{t}(\mathrm{FNM})\right)$ denotes the probability that Freddie Mac defaults within the first five years under the condition that Fannie Mae also defaults within the first five years. Applying (27), the following two conditional probabilities can be calculated:

$$
\begin{aligned}
& \mathbb{Q}\left(D F_{5}(\mathrm{FNM}) \mid D F_{5}(\mathrm{FRE})\right)=54.01 \%, \\
& \mathbb{Q}\left(D F_{5}(\mathrm{FRE}) \mid D F_{5}(\mathrm{FNM})\right)=23.36 \% .
\end{aligned}
$$

In other words, the probability of default for Fannie Mae in the first five years under the condition that Freddie Mac defaults is $54.01 \%$, as well as $23.36 \%$ for Freddie Mac given that Fannie Mae defaults. These probabilities are approximately four times as high as the unconditional probabilities of $12.97 \%$ and $5.61 \%$, respectively, which would be observable if the events of default occurred independently.

Considering the simulated time series, in 6,698 of the 10,000 cases, Fannie Mae has been the first company to default; in 3,287 cases Freddie Mac went bankrupt first. In 2 cases, neither of the two companies defaulted, and in 13 cases both of them defaulted exactly the same day. The dependence structure becomes also visible when we look at Figure 6. Figure 6 plots the difference between the first and second defaults. For example, the graph shows that the probability that the defaults of both mortgage banks take place within 365 days amounting to $15.63 \%$. In other words, with a probability of $15.63 \%$ the second company defaults no later than one year after the first company has defaulted. However, note that there is a bias in that graph because only 100 years are simulated.

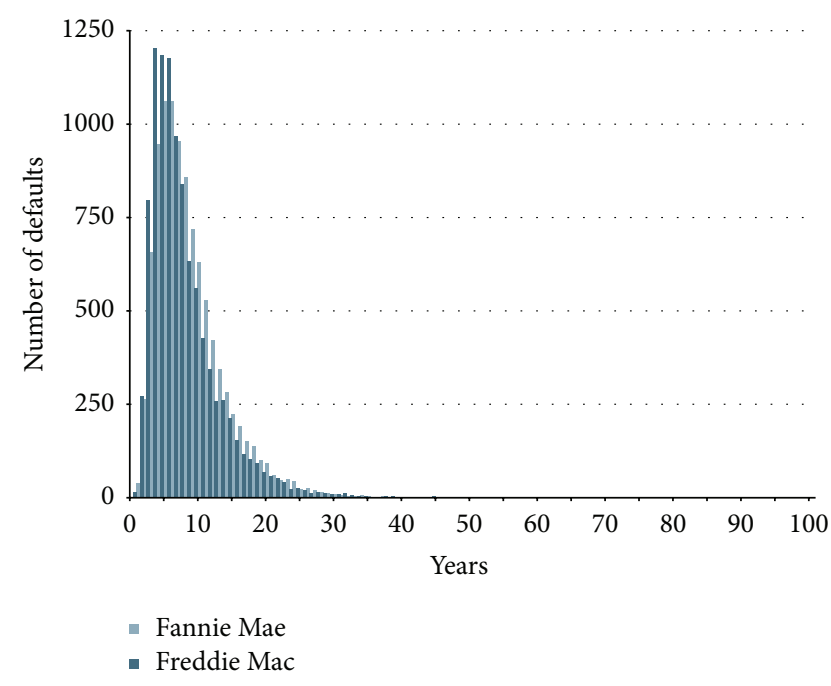

FIGURE 7: Defaults of simulated time series (July 2008).

Yet, the number of cases where one company does not default over the considered 100 years is very small.

So far, the study concentrated on the condition of Fannie Mae and Freddie Mac right before the outbreak of the crisis analyzing their situation in July 2007. The following question arises: how the default probability and the situation of both mortgage banks changed before they were placed into federal conservatorship (summer of 2008). The data of July 2002 until June 2008 is used to examine Fannie Mae and Freddie Mac and their default risks starting on July, 2008. The risk-free rate $r$ is $3.77 \%$ and their debt ratios changed to $D_{\mathrm{FNM}}(0)=28.1$ and $D_{\text {FRE }}(0)=26.7$.

The fitted parameters for Fannie Mae based on the new time series are

\begin{tabular}{c|cccc} 
Est. parameters & $\widehat{\mu}$ & $\widehat{v_{\infty}}$ & $\widehat{\kappa_{v}}$ & $\widehat{\varepsilon_{v}}$ \\
Fannie Mae & 0.0339 & 0.00004283 & 7.005 & 0.01842 \\
\hline Freddie Mac & 0.03293 & 0.00008034 & 7.107 & 0.0335
\end{tabular}

The correlation parameter is $\rho=0.9476$.

Comparing these parameters to the previous ones, they first of all differ in the drift which has decreased for both companies (by more than the risk-free rate has decreased). The long-term variance has increased, in particular for Freddie Mac, which results in higher risk for the asset time series to fall below the debt, and therefore the risk for the company to default. Furthermore, the correlation between the Wiener processes of the assets has significantly increased from 0.7026 to 0.9476 .

As before, 10,000 pairs of time series are simulated with those parameters over a time horizon of 100 years. Figure 7 visualizes the distribution of the time of default of Fannie Mae and Freddie Mac. What can be noticed at first sight is the fact that Fannie Mae and Freddie Mac default much earlier than before. Furthermore, now Freddie Mac seems to default earlier than Fannie Mae which is due to the lower drift and a higher variance compared to Fannie Mae and the fact that, furthermore, the difference of their leverage 


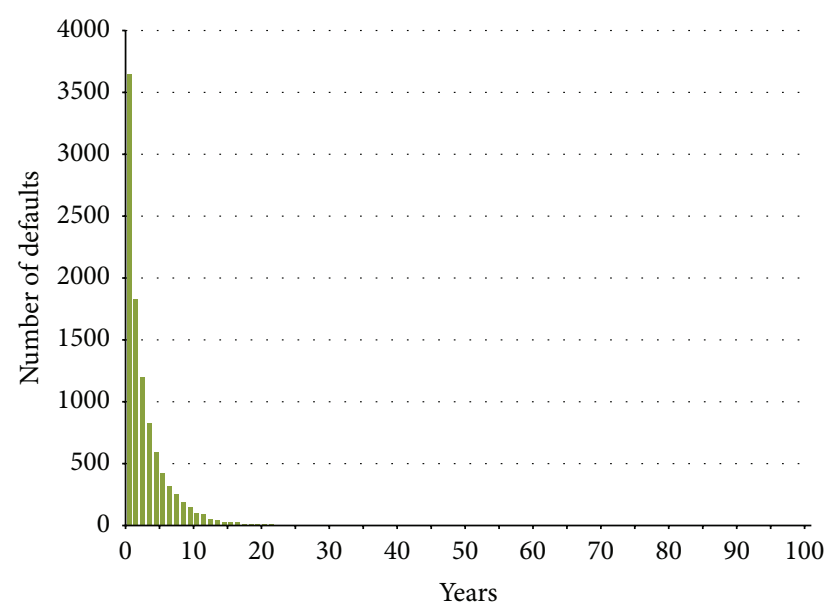

FIGURE 8: Time difference between first and second default (July 2008).

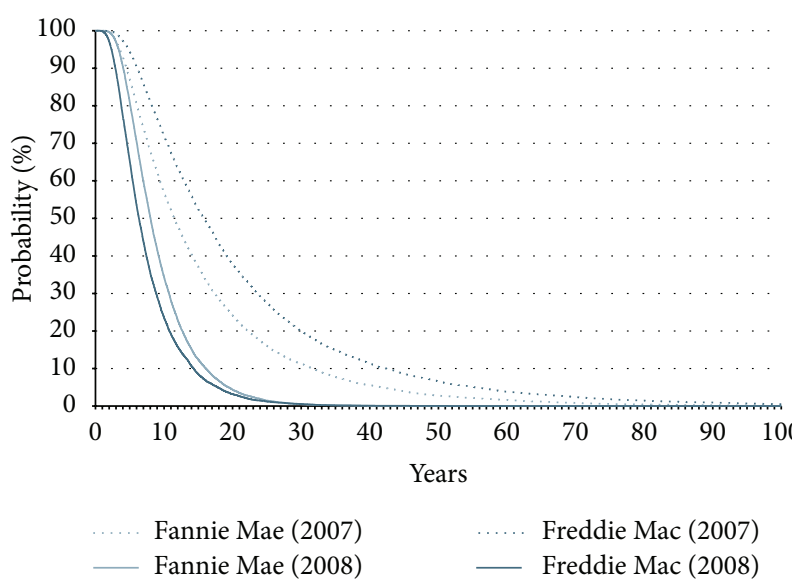

Figure 9: Survival probabilities for Fannie Mae and Freddie Mac (July 2008).

ratios is not as large as before. Now, in 2,917 of the 10,000 simulated cases, Fannie Mae defaults before Freddie Mac. In 6,995 cases, Freddie Mac is the first to default. In none of the cases, both companies survive 100 years, and in 88 cases, they default exactly the same day. Figure 8 examines the difference between the times when they default. With a probability of $36.47 \%$, both companies default in the same year; that is, the second company defaults no later than 365 days after the first company has gone bankrupt.

Figure 9 compares the survival probabilities of Fannie Mae and Freddie Mac for the two examined time periods, starting in July 2007 and July 2008. The graph truly speaks for itself. Whereas the probability to survive the next five years has been $87.03 \%$ for Fannie Mae and $94.39 \%$ for Freddie Mac in July 2007, this probability decreases to $80.97 \%$ and
$65.27 \%$, respectively. This corresponds to probabilities to default within the first five years of

$$
\begin{aligned}
& \mathbb{Q}\left(D F_{5}(\mathrm{FNM})\right)=19.03 \%, \\
& \mathbb{Q}\left(D F_{5}(\mathrm{FRE})\right)=34.73 \% .
\end{aligned}
$$

As the joint probability for both mortgage banks to default is

$$
\mathbb{Q}\left(D F_{5}(\mathrm{FNM}, \mathrm{FRE})\right)=16.25 \%,
$$

the conditional probabilities are

$$
\begin{aligned}
& \mathbb{Q}\left(D F_{5}(\mathrm{FNM}) \mid D F_{5}(\mathrm{FRE})\right)=46.79 \%, \\
& \mathbb{Q}\left(D F_{5}(\mathrm{FRE}) \mid D F_{5}(\mathrm{FNM})\right)=85.39 \% .
\end{aligned}
$$

These conditional probabilities exemplify the even increased dependence of the events of default of Fannie Mae and Freddie Mac.

\section{Conclusion}

In this paper, we extended the structural credit model under stochastic volatility in [1] to a multi-dimensional model. We allow the underlying asset processes of the companies to develop with a correlation to incorporate dependence structures among them. This joint model allows for many of the stylized facts known in the literature for equity series like stochastic volatility and leverage effect. In addition to the estimators with the help of which we can gain the parameters for the single processes, we derived an estimator for the correlation parameter. In a recovery test, this estimator proved to capture the real correlation with high precision. With the help of the presented model, the situation of the two mortgage banks Fannie Mae and Freddie Mac was scrutinized. Their default risk was examined at two points in time: mid-2007 and mid 2008. It showed that the already severe situation of Fannie Mae and Freddie Mac before the crisis is compared to the situation in July 2008, when a near end of the two GSEs was already foreseeable, considering the dramatic increase in the default probabilities. For example, their probabilities to survive the next five years decreased from $87.03 \%$ to $80.95 \%$ for Fannie Mae and from $94.39 \%$ to $65.27 \%$ for Freddie Mac. What can also be observed from the case of Fannie Mae and Freddie Mac is that the events of a default are more likely to coincide than to occur independently, which goes in line with the positive correlation of their asset processes. Also the correlation increases between 2007 and 2008 from 0.70 to 0.95 . The probability for one company to default given that the other one also goes bankrupt is severely higher than under the assumption of independence. For example, the unconditional probabilities for Fannie Mae and Freddie Mac in July 2008 to default within the next five years amounted to $19.03 \%$ and $34.73 \%$. Given that one company defaults, the other would default with a higher probability of $46.79 \%$ (Fannie Mae) or $85.39 \%$ (Freddie Mac). This confirms the importance of considering dependence structures when evaluating default probabilities of a portfolio. 


\section{Appendix}

\section{A. Proofs}

A.1. Proof of Proposition 1. Note that in the theorem and in the proof, $v_{X}$ denotes the variance of the process $X(t)$ and $\sigma_{X}$ its respective standard deviation. $v(t)$ without index denotes, as defined, the variance of the asset process $A(t)$. Accordingly, $\mu_{X}$ denotes the drift term with respect to $X$. In the following, we always assume that no default has occurred, that is, that $\mathbf{1}_{\{\tau>t\}}=1$. We first derive the dynamics of $\ln C(t)$ applying Itô Calculus as

$$
d \ln C(t)=\mu_{\ln C} d t+\sqrt{v(t) g(t)} d Z(t) .
$$

Thus, we have

$$
\begin{aligned}
& \langle d \ln C(t)\rangle=v_{\ln C(t)} \cdot \mathbf{1}_{\{\tau>t\}} \quad \text { with } v_{\ln C(t)}=v(t) \cdot g(t), \\
& \left\langle d \ln C_{i}(t), d \ln C_{j}(t)\right\rangle=\sqrt{v_{i}(t) v_{j}(t) g_{i}(t) g_{j}(t)} \cdot \mathbf{1}_{\left\{\tau_{i}>t\right\}} \\
& \cdot \mathbf{1}_{\left\{\tau_{j}>t\right\}} \cdot \rho d t
\end{aligned}
$$

The product rule gives us the dynamics of $v_{\ln C(t)}$ as

$$
\begin{aligned}
d v_{\ln C(t)}= & \mu_{v_{\ln C}} d t-2 v^{3 / 2}(t) g(t) \cdot \frac{D(t)}{C(t)} d Z(t) \\
& +\varepsilon_{v} \sqrt{v(t)} g(t) d Z^{v}(t) .
\end{aligned}
$$

For the correlation we need $\left\langle d \ln C(t), d v_{\ln C(t)}\right\rangle$ and $\sqrt{\langle d \ln C(t)\rangle\left\langle d v_{\ln C(t)}\right\rangle}$ which together give us the result

$$
\frac{\left\langle d \ln C(t), d v_{\ln C(t)}\right\rangle}{\sqrt{\langle d \ln C(t)\rangle\left\langle d v_{\ln C(t)}\right\rangle}}=-\frac{2 v(t) \cdot(D(t) / C(t))}{\sqrt{4 v^{2}(t)(D(t) / C(t))^{2}+\varepsilon_{v}^{2}}} .
$$

This result can also be written as

$$
-\frac{v(t)}{\sqrt{v^{2}(t)+((1 / 2) \varepsilon \cdot(C(t) / D(t)))^{2}}} .
$$

A.2. Proof of Proposition 3. The estimators expressed in (20) have already been proved in [1]. Similarly, we can also apply the limit theorem which is stated in [1] here as

$$
\frac{1}{n} \sum_{i=0}^{n-1} R_{1}(i+1) R_{2}(i+1) \stackrel{\text { a.s. }}{\longrightarrow} \mathbb{E}\left[R_{1}(1) R_{2}(1)\right] .
$$

Now, the expected value is calculated as

$$
\begin{aligned}
\mathbb{E}[ & \left.R_{1}(1) R_{2}(1)\right] \\
=\mathbb{E}[ & \left.\mathbb{E}\left[R_{1}(1) R_{2}(1) \mid\left(\bar{V}_{1}, \bar{V}_{2}\right)\right]\right] \\
=\mathbb{E}[ & \operatorname{Cov}\left(R_{1}(1), R_{2}(1) \mid\left(\bar{V}_{1}, \bar{V}_{2}\right)\right) \\
& \left.+\mathbb{E}\left[R_{1}(1) \mid \bar{V}_{1}\right] \cdot \mathbb{E}\left[R_{2}(1) \mid \bar{V}_{2}\right]\right] \\
\approx \mathbb{E} & {\left[\rho \sqrt{\bar{V}_{1} \cdot \bar{V}_{2}}+\left(\sqrt{\Delta} \mu_{1}-\frac{1}{2} \sqrt{\Delta} \bar{V}_{1}(1)\right)\right.} \\
& \left.\times\left(\sqrt{\Delta} \mu_{2}-\frac{1}{2} \sqrt{\Delta \bar{V}_{2}}(1)\right)\right] \\
=\rho & \cdot \mathbb{E}\left[\bar{V}_{1}^{1 / 2}(1)\right] \mathbb{E}\left[\bar{V}_{2}^{1 / 2}(1)\right] \\
+ & \left(\sqrt{\Delta} \mu_{1}-\frac{\sqrt{\Delta}}{2} \mathbb{E}\left[\bar{V}_{1}(1)\right]\right) \\
& \left(\sqrt{\Delta} \mu_{2}-\frac{\sqrt{\Delta}}{2} \mathbb{E}\left[\bar{V}_{2}(1)\right]\right)
\end{aligned}
$$

(by Cauchy-Schwarz Inequality we have $\leq$ but for small $\Delta$ it works well as an approximation). Therefore, (21) holds.

From [12] the stationary distribution of the variance $v$ is known to be a Gamma distribution with parameters $2 v_{\infty} \kappa_{v} / \varepsilon_{v}^{2}$ and $2 \kappa_{v} / \varepsilon_{v}^{2}$. Furthermore, the moment of order $p$ of the stationary distribution is according to [12] as

$$
m(p)=\frac{\Gamma\left(2 v_{\infty} \kappa_{v} / \varepsilon_{v}^{2}+p\right)}{\Gamma\left(2 v_{\infty} \kappa_{v} / \varepsilon_{v}^{2}\right)}\left(\frac{\varepsilon_{v}^{2}}{2 \kappa_{v}}\right)^{p} .
$$

Assuming that $\Delta \rightarrow 0$ and applying Appendix A.2 with $p=$ $1 / 2$ gives

$$
\mathbb{E}\left[\bar{V}^{1 / 2}(1)\right] \stackrel{\Delta \rightarrow 0}{=} \frac{\Gamma\left(2 v_{\infty} \kappa_{v} / \varepsilon_{v}^{2}+0.5\right)}{\Gamma\left(2 v_{\infty} \kappa_{v} / \varepsilon_{v}^{2}\right)} \cdot \frac{\varepsilon_{v}}{\sqrt{2 \kappa_{v}}} .
$$

\section{References}

[1] M. Escobar, T. Friederich, M. Krayzler, L. Seco, and R. Zagst, "Structural credit modeling under stochastic volatility," International Journal of Statistics and Probability, vol. 1, pp. 7-20, 2012.

[2] R. C. Merton, "Theory of rational option pricing," Bell Journal of Economics and Management Science, vol. 4, pp. 141-183, 1973.

[3] F. Black and J. Cox, "Valuing corporate securities: some effects of bond indenture provisions," Journal of Finance, vol. 31, no. 2, pp. 351-367, 1976.

[4] S. Heston, "A closed-form solution for options with stochastic volatility with applications to bond and currency options," The Review of Financial Studies, vol. 6, no. 2, pp. 327-343, 1993.

[5] W. Feller, "Two singular diffusion problems," Annals of Mathematics, vol. 54, pp. 173-182, 1951.

[6] J. C. Cox, J. E. Ingersoll Jr., and S. A. Ross, "A theory of the term structure of interest rates," Econometrica, vol. 53, no. 2, pp. 385407, 1985.

[7] R. Zagst, Interest-Rate Management, Springer, Berlin, Germany, 2002. 
[8] M. Escobar, T. Friederich, M. Krayzler, L. Seco, and R. Zagst, "A general structural approach for credit modeling under stochastic volatility," Journal of Financial Transformations, vol. 32, pp. 123-132, 2011.

[9] F. Black, "Studies in stock price volatility changes," in Proceedings of the Business Meeting of the Business and Economic Statistics Section, American Statistical Association, pp. 177-181, 1976.

[10] A. Eydeland and K. Wolyniec, Energy and Power Risk Management: New Development in Modeling, Pricing and Hedging, Wiley, 2003.

[11] C. Walter and J. Lopez, "Is implied correlation worth calculating? Evidence from foreign exchange options and historical data," Research Paper 9730, Federal Reserve Bank of New York, 1997.

[12] V. Genon-Catalot, T. Jeantheau, and C. Larédo, "Stochastic volatility models as hidden Markov models and statistical applications," Bernoulli, vol. 6, no. 6, pp. 1051-1079, 2000. 


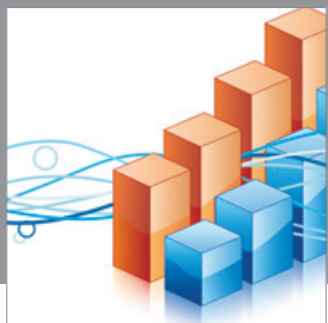

Advances in

Operations Research

mansans

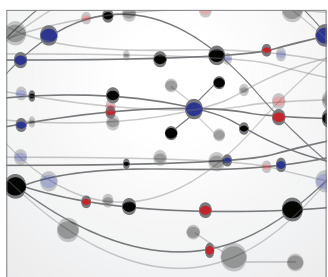

The Scientific World Journal
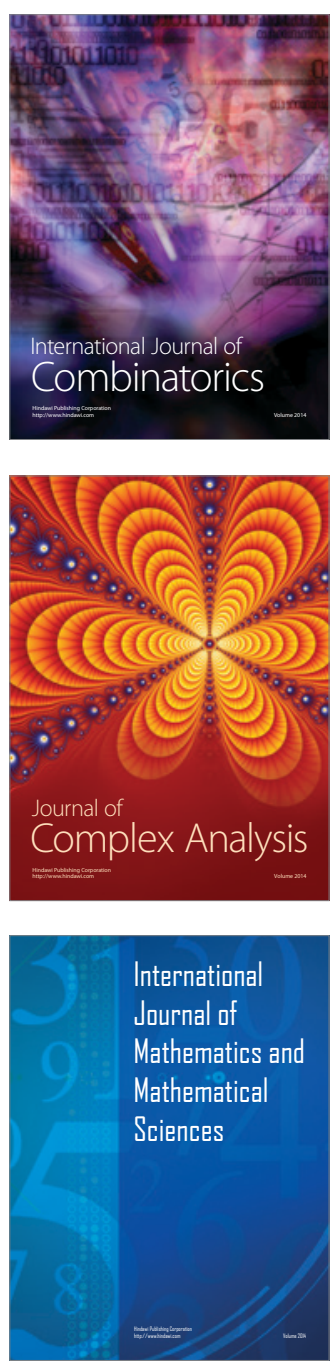
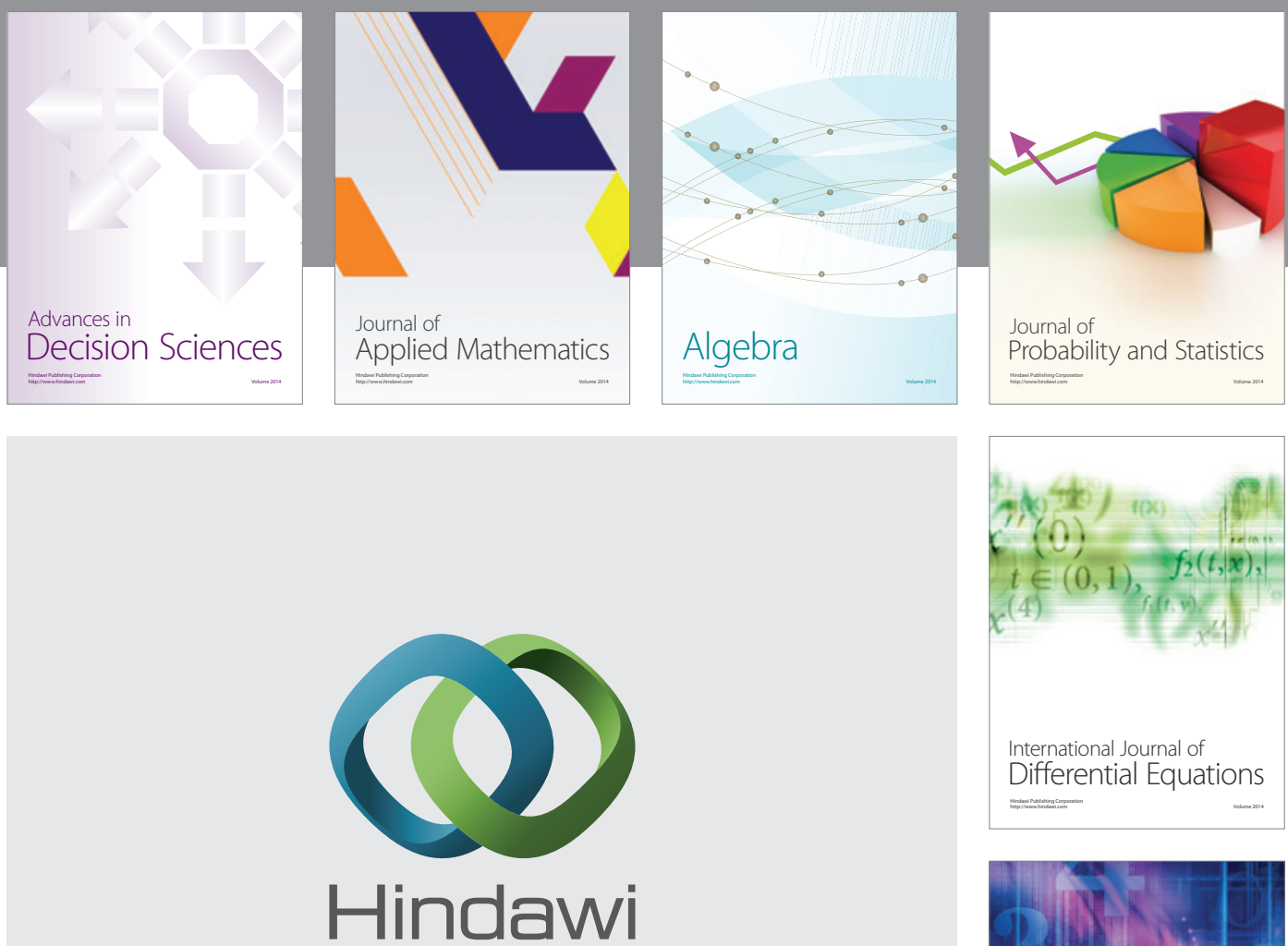

Submit your manuscripts at http://www.hindawi.com
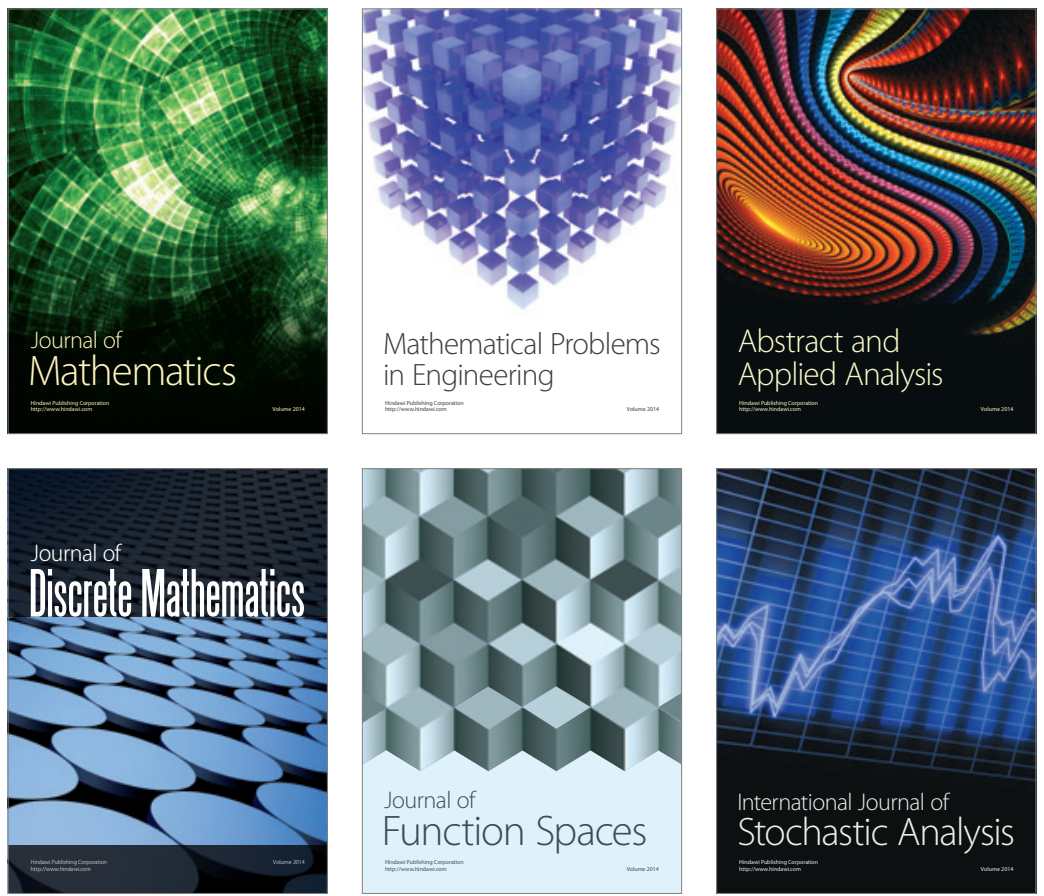

Journal of

Function Spaces

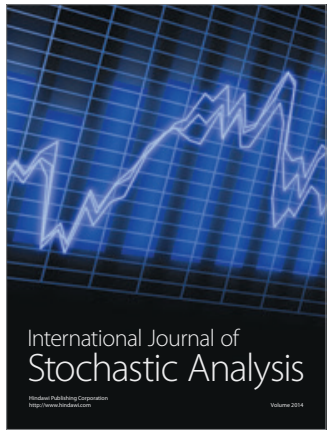

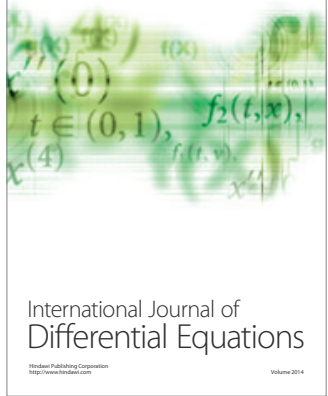
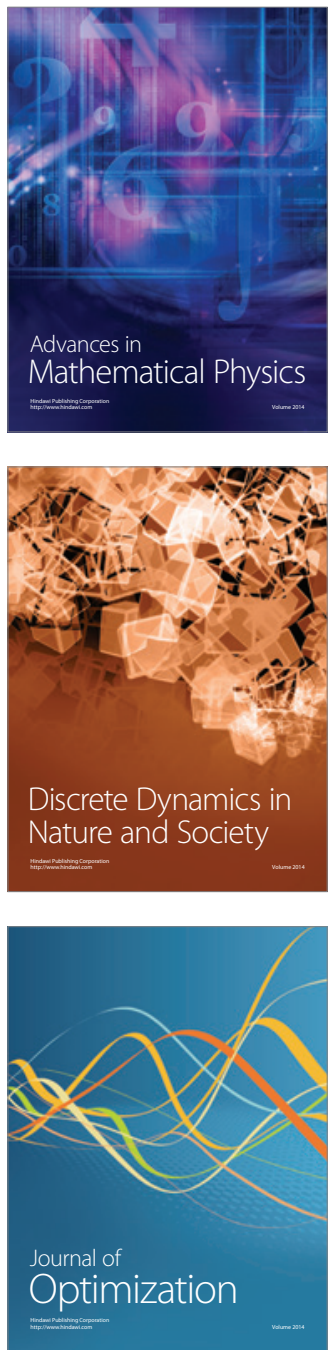